\title{
The Effect of Workforce Restructuring on Withdrawal Behavior: The Role of Job Insecurity, Career Plateau and Procedural Justice*
}

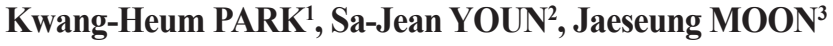

Received: May 05, 2020 Revised: May 18, 2020 Accepted: June 10, 2020

\begin{abstract}
This study examines the direct effect of workforce restructuring on the withdrawal behavior and mediating effect of perceived job insecurity. Empirically it also explores the moderating effect of career plateau and procedural justice on the above relationship. The study focuses on the mediating role of job insecurity and the moderating role of career plateau in relations to procedural justice, which will concentrate on the relationship between workforce restructuring and withdrawal behavior. For the empirical study, we collected and analyzed 442 survey data from employees of Korean companies. SPSS 24 is used for reliability, correlation and regression analysis. The results of the empirical analysis are as follows. First, perceived job insecurity mediated the relationship between workforce restructuring and withdrawal behavior. Second, content career plateau had a negative moderating effect on the relationship between workforce restructuring and job insecurity. Finally, the moderating effect of procedural justice was not supported. This research extend workforce restructuring and career plateau related studies; by exploring the mediating variable and moderating variable on the relationship between workforce restructuring and the pertaining outcomes. Based on the results, we provide theoretical and practical implications along with future research recommendations.
\end{abstract}

Keywords : Workforce Restructuring, Career Plateau, Job Insecurity, Procedural Justice, Withdrawal Behavior

JEL Classification Code: D23, M12, M54

\section{Introduction}

Restructuring of the work force has always been regarded by companies as the most obvious way to improve costs and re-strengthen its basic core, which in the end should obtain efficiency and effectiveness (Cameron, 1994). However, it needs to be reminded that the long-term competitiveness of a company renders not only from a specified area of scope. The core strength of a company lies in the positive change

\footnotetext{
*This paper was modified and developed from the PhD thesis of the first author

${ }^{1}$ First Author. PhD in Business Administration, Email: khpark1007@naver.com

${ }^{2}$ Assistant Professor, School of Business Administration, Daejeon University, Korea. Email: sjyoun56@dju.kr

${ }^{3}$ Corresponding Author. Associate Professor, School of Business Administration, Daejeon University, Korea. Email: moonjs@dju.kr

(c) Copyright: The Author(s)

This is an Open Access article distributed under the terms of the Creative Commons Attribution Non-Commercial License (http://Creativecommons.org/licenses/by-nc/4.0/) which permits unrestricted noncommercial use, distribution, and reproduction in any medium, provided the original work is properly cited.
}

from the entirety of its organization and from the societal support of its surrounding community - customers, market conditions, business structure, product competitiveness, financial structure and the merits of its employees and organization.

On the other hand, some find labor restructuring to be a positive tool. It is believed to enable cost efficiency and a clean-out of insufficient management, whilst encouraging a boost in the overall environment of the firm, as well as in its flexibility and productivity along with creativity of the personnel (Mone, 1997). But, when observing the results of the numerous research in regards to labor restructuring, it is evident that negative results are greater than that of the positive (Meuse, Vanderheiden, \& Bergmann, 1994). In addition, Ashford et al. (1989) has proven that restructuring of the workforce negatively deteriorates the trust and the attentiveness one may have for its company.

As of present, amongst the research on restructuring the focus of the studies mostly seem to center upon the theoretical side of the effect and the impact generated by restructuring. Within empirical research as well, majority of the studies seem to sway towards the direct effect coming 
from restructuring of the workforce. Hence, clearly there is a lack of sufficient information as well as credible foresight, in regards to the impact restructuring of the workforce may have incurred on the psychological domain (Park \& Yang, 2002). With equal amount of claims representing both the positive aspect of restructuring (Mone, 1997) as well as that of the negative (Meuse, Vanderheiden, \& Bergmann, 1994), the following possibilities seemed to be acknowledged variables which may impact the outcome of restructuring can either be of a mediating variable or that of a moderating variable. Further research was made to find more depth to the moderating variable, but overall the scope remains quite limited, as majority of its focus centers on that of the special characteristics of the individual, followed by procedural justice of the restructuring process (Brockner, Tyler, \& Cooper-Schneider, 1992; Morrison \& Robinson, 1997). Therefore, we need to understand clearly how restructuring effects the process of the variables that impact the actual outcome; we need to obtain practical insight, and explain the results of prior research that of which have differing perspectives, by investigating the variables that either boosts or offsets the outcome (Meckler, Drake, \& Levinson, 2003).

In short, this study is to assess the process of the effect of restructuring to the organization, and to explore the moderating factors, which affect the relationship. In detail, the paper is to examine the mediating effect of job insecurity perception, the moderating effect of career plateau and the procedural justice within the relationship between restructuring and withdrawal behavior.

\section{Literature Review and Hypothesis}

\subsection{Workforce Restructuring}

Depending on the scholars, the definition of restructuring has various interpretations of its meaning with also various perceptions. For the likes of Cascio (1993), he approaches restructuring from a pure "job function". He defines restructuring as a method to reduce waste within job execution - strategy of cost efficiency - deliberately removing the job or the responsibility based under a plan. But at present, the definition of restructuring is generally used when referring to workforce restructuring or the deliberate reduction of labor (Jung, 2017; Mckinley, Sanchez, \& Schick, 1995). The execution of restructuring by definition is not simply about job-cuts, but more about generating efficiency via finding the most effective synergy in the ability of the labor and the job function in question. On the contrary however, it seems to be the former where in general, restructuring equals job loss - for the employees, restructuring means a possible labor cut, not a method of strategic repositioning to upgrade the organization (Choi \& Gurung, 2019).
According to Mone (1997), he believes the expectations from workforce restructuring should be monitored from the two categories - the former being cost efficiency, and the latter being the opportunity to clean-out insufficient management, whilst encouraging a boost in the overall environment of the firm, as well as in its flexibility and productivity along with creativity of the personnel. In particular, as the redundant management is replaced, it is assumed that the individual can gain more access to an increase of responsibility that then can naturally progress to motivating oneself to an upgraded level of productivity. In the end, depending on the business strategy, in order to position and foster the most appropriate right resource and right person for the execution of the strategy, workforce restructuring is sought to be a very helpful tool. Also for the constant upgrade of labor and organization quality, it is rendered that sufficient outcomes of workforce restructuring is positive for the firm (Jung, \& Moon, 2015; Lee, 2018).

Nevertheless when observing the results from various empirical research on workforce restructuring, rather than the positive, there are more reports which claim the opposite (Meuse, Vanderheiden, \& Bergmann, 1994). Cascio (1993) claims in his research on downsizing, after workforce restructuring, the indirect costs for the hiring of new employees plus the training of this new workforce takes up $1 / 3$ of their first year salary; also, the pay out of dismissal pay which is part of the direct expense, ends up adding to the increase of costs.

Just as well, there are two opposite claims in regards to the effect coming from workforce restructuring on the individual. Brockner (1988) notes that because of the fear of losing one's job, in order to maintain ones occupation, the individual is said to make more effort in hope of keeping its position. In other words, to avoid the possibility of being fired, the individual will increase productivity and prove its value to the firm. Despite these claims above, from the many empirical research, the general outcomes of restructuring are said to be quite the contrary. Due to fear from the insecurity of losing one's job (within the midst of restructuring), plus low self-esteem and trust for the firm as a whole, individuals are noted to be at a very passive and negative state with an extremely weak focus and hardly any desire to take risks (Ashford et al., 1989). Greenhalgh and Rosenblatt (1984) points out that the higher and the more unstable the possibility may be in losing job security, lesser will there be efforts made by the employee to achieve the company's goal. Roskies and Louis-Guerin (1990) share similar views that if job security is unstable, employees will find no motivation to be passionate about the work - believing that their time and energy for the firm is a waste. Herewith, workforce restructuring can trigger and awaken the fear from the instability of job security and the breach of the so called 
psychological contract (Shore \& Tetrick, 1994). Thus, the employees feel and become distant with the organization that leads to negative outcomes in their job performance.

Numerous empirical research confirms job insecurity perception is the cause that deteriorates psychological well-being (Dekker \& Schaufeli, 1995; Ferrie et al., 1998), also which disrupts organizational commitment and job satisfaction (Heaney, Israel \& House, 1994; Rosenblatt \& Ruvio, 1996) and finally triggering turnover intention. Such factors bring about opposite results in perceived performance and in resistance to change.

\subsection{Restructuring and Withdrawal Behavior}

Withdrawal behavior is an unproductive outcome, which in the form of laziness, tardiness, absence, and turnover along with its contributions to the organization (Colquitt et al., 2014). According to previous research, the effect restructuring has on the workforce is explained using the psychological contract theory (Rousseau, 1995). Workers whom have experienced restructuring have a tendency to believe that the firm has betrayed them and have breached the psychological contract. Hence if the individual feels the contract is breached due to restructuring, the general response tends to be uncontrollable rage and resentment to the organization; triggering a much serious level of vengeful behavior than in mere times of conflict in regards to one's expectations with the firm (Robinson \& Rousseau, 1994). This sort of breach of the psychological contract can be realized not only from threats of the objective, but also from the subjective such as employment uncertainty. Singh (1998) explains that employees, whom have had the experience of being fired from downsizing, tend to have very low trust for its future employer plus, there is an increase of aggressiveness in protecting one's interests. Downsizing not only effects the psychological contract of the employees leaving the firm, but also the remaining employees as well. From research by Turnley and Feldman(1998), in comparison to those with no experience, the remaining employees whom have survived the downsizing and also the organizational change (as the firm rebuilds), are said to be more sensitive in regards to the implications from the breach of the psychological contract. Downsizing ends up destroying the psychological contract of the tradeoff between loyalty to the firm and lifetime employment (Kets de Vries \& Balazs, 1997).

It can also be explained from the perspective of the social exchange theory (Blau, 1964). According to the theory, the relationship between the employer and the employee are said to be established when the exchange of benefits can enable achievements in salary, support and recognition. Thus through this relationship of "exchange", the attitude and behavior of the individuals can be determined; if the relationship starts to deteriorate, most likely withdrawal behavior will be displayed (by the employees) either in the form of psychological (slow down), or physical withdrawal (tardiness, absenteeism and early leave). Herewith, in regards to the discussion and the results from empirical research, the following hypothesis was established.

Hypothesis 1: Workforce restructuring is positively related to the employee's withdrawal behavior.

\subsection{Workforce Restructuring and Job Insecurity Perception}

The general definition of job insecurity is the awareness of one's helplessness when maintaining the job is impossible, whilst job security is continuously being challenged (Ashford, et al., 1989; Greenhalgh \& Rosenblatt, 1984). Most frequently, organizational change is referred to by the workforce, as the main cause of their helplessness and threat from control. In majority the factors that cause organizational change are M\&A, downsizing, reshuffling, and systematic change from new technology; however the most feared amongst them, are when the individual gets fired or demoted (Ashford, Lee, \& Bobko, 1989; Brockner, 1988). Organizational change effects the psychological contract between the organization and the employee, which will enhance the concern and the worry in its inability to maintain control of job security (Schweiger \& Invancevich, 1985). Ashford et al. (1989) also highlights the inability to control, as the cause of job insecurity. Under the psychological contract, the two parties need to be clear as to what will be exchanged. This bind from the contract will give a sense of control for the two parties, which should enable them to control within reason, if not at least to predict and prepare for future uncertainty. Therefore, given that the sense of control and the ability to predict is important for the workforce, naturally the response to organizational change is negative - regarded as a direct threat to control and thus the reason of job insecurity. Once restructuring has taken place, evidently, the job insecurity the remaining workers may confront will not only be effected by simply being fired, but also by the various outcomes such as reshuffling of the job position, the title, promotion, demotion and the like (Ashford et al., 1989). Brockner et al. (1987) also confirms the most significant factor and direct cause of job insecurity is the possible threat of being fired as well as simply being fired. Herewith, in regards to the discussions above and the results from empirical research, the following hypothesis was established.

Hypothesis 2: Workforce restructuring is positively related to the employee's job insecurity perception.

\subsection{Job Insecurity Perception and Withdrawal Behavior}

Job security enables the employee to display one's ability and attributes fairly to the firm, which then can gain 
recognition in its presence and contribution; thus achieving the ideal expectations of equal compensation - such a mechanism can be understood as a relationship of social exchange (Mowday, Porter \& Steers, 1982). Hence, within the process of social exchange, job insecurity perception becomes the reason of unfair perception, which in turn will trigger job dissatisfaction and eventually deteriorate ones commitment to the firm. Moreover, workers will depend on the firm via the bound of the psychological contract, but once job insecurity is realized, the psychological contract will come to a halt. If such is the case, it can be assumed that once the firm tries to offer this destructive venue called restructuring, individuals will remove its social attachment from the firm. Even the empirical research indicates that job insecurity perception generates negative effects to the employees. For instance, job satisfaction (Ivancevich \& Matteson, 1980), organizational commitment (Forbes, 1985) and turnover intention (Arnold \& Feldman, 1982) all are negatively affected by job insecurity perception and that of which in the end will lead to a fall out in job performance (Ackerman, 1982).

On the other hand, researchers are insisting that there is a negative relationship between organizational commitment and withdrawal behavior. In short, it is said that higher the organizational commitment, lesser the withdrawal behavior; lower the commitment, increasingly more is the withdrawal behavior (Colquitt et al., 2014). Observing from such a perspective, we can assume that job insecurity negatively effects organizational commitment, while a positive outcome for withdrawal behavior.

Even within empirical research, it is noted that the greater job insecurity becomes (due to workforce restructuring), one of the corresponding strategies is withdrawal behavior. For example, Davy et al. (1997) while studying the relationship and the effectiveness between job insecurity and withdrawal cognitions, it was reported that job insecurity effects withdrawal cognitions. Based on the discussion above and results from empirical research, the following hypothesis was established.

Hypothesis 3: Job insecurity perception is positively related to withdrawal behavior.

\subsection{Mediating Effect of Job Insecurity Perception}

Amongst the relationship between workforce restructuring, emotional commitment and withdrawal behavior, the mediating effect of job insecurity perception can be explained from the collective gathering of hypothesizes made prior. In other words, it notes that job insecurity (for the worker) goes up, as restructuring for the workforce continues onward, which then in turn brings forth withdrawal behavior. Also within the midst of workforce restructuring, as employees begin to realize the psychological insecurity of becoming possibly laid-off themselves, though discouraging, organizational commitment will start to whither, whilst the increase in withdrawal behavior.

It can be also explained based on the conservation of resources theory. According to the theory, even if resources become lost or enormous amounts of resources are invested, unless a sufficient amount of success is achieved, inevitably psychological stress will be induced. The main reason stress occurs (based on this theory) is said to be due to the large insufficient amount of resources required for the job at hand. Therefore, whenever the individual's withdrawal behavior faces a crisis, the natural instinct to protect oneself from being influenced by the outside environment seems to be well in place. Davy et al. (1997) from the results of his research, suggested job insecurity from workforce restructuring will negatively affect withdrawal perception. According to the conservation of resources theory, the reason workers are displaying withdrawal behavior after becoming aware of the perception of job insecurity (due to restructuring), is said to be the avoidance effort to lessen the stress from job insecurity (Ashford et al., 1989; Greenhalgh \& Rosenblatt, 1984). Herewith, in regards to the discussion and the results from empirical research, the following hypothesis was established.

Hypothesis 4: Job insecurity perception mediates the relationship between workforce restructuring and withdrawal behavior.

\subsection{Moderating Effect of Career Plateau}

Bardwick (1986) defines career plateau by broadening the existing scope; encompassing not only the traditional concept such as the awareness of structural limits (of the vertical and of the horizontal growth), but also limitations in areas of responsibility and of the challenging will, in regards to the content of its current job performance. To sum up, if possibilities of a shift in one's work are very low (whether upward, vertically or horizontally), it will be referred to as structural plateau. If the sense of responsibility and the challenging will for the current job also shows no growth, it will be referred to as content plateau - a state where the individual feels that there is nothing new nor more to learn in delivering the body of work. Hence, the sense of responsibility and the passionate drive for the job just as well falls flat (Lentz \& Allen, 2009). Perception of vertical upward possibilities in future job promotions, as well as possibilities of growth via horizontal movements (within the firm) are said to affect the individual's attitude and behavior in light of the organization (West, Nicholson, \& Fees, 1990). To elaborate, workers whom have not realized career plateau in their various areas of job performance, in comparison to 
those whom have, are continuously generating impressive outcomes. Nevertheless, those individuals whom are aware of the plateau start to show a fall in commitment, a slowdown in its productivity and even an increase in costs.

After restructuring, the perception of job insecurity by the remaining employees, depending on how they are perceiving career plateau can make the biggest difference.

The workers whom believe that there is a barrier as to achieving vertical promotions, horizontal movements, thus facing structural plateau (within the firm) are, the lowest of achievers, the highest in rank, the longest in employment, the oldest in age and female workers based on gender issues. In general, since the workers that face structural plateau frequently end up becoming candidates (of restructuring), individuals whom are highly aware of the plateau seem to consider the inevitable of getting fired. Therefore, generating the unavoidable rise in job insecurity perception. Also, outside of the obvious setbacks from losing one's job, with the life span cycle longer particularly for the older generation at present, the impact from retirement or job loss is becoming a graver issue than before. Hence, once again, which triggers a rise in job insecurity perception. Herewith, in regards to the discussion and the results from empirical research, the following hypotheses were established.

Hypothesis 5a: Career plateau moderates the relationship between workforce restructuring and job insecurity perception, such that the relationship becomes stronger when structural career plateau is higher.

Hypothesis 5b: Career plateau moderates the relationship between workforce restructuring and job insecurity perception, such that the relationship becomes stronger when content plateau is higher.

\subsection{Moderating Effect of Procedural Justice}

Studies on factors that can alleviate the negative effect coming from job insecurity was also pursued by empirical research. The leading moderating factor suggested by the research was justice perception (Brockner \& \& Wiesenfeld, 1996; Daniel et al., 1998; Folger \& Konovsky, 1989). When the fired individual experiences an outcome, they are influenced by the individual's parameter of justice during the time and process of which the individual loses their job (Daniel et al., 1998). Within the empirical research, in majority, distributive justice and procedural justice are considered. If distributive justice is about whether it is fair in receiving the reward as a result of individual effort or of contributions (Folger \& Cropanzano, 1998), procedural justice is the individual's perception of fairness, based on the official procedures being established in the midst of decision making.
Primarily, based on procedural justice, speculations in attitude and emotional response are pursued. For example, when comparing the relationship between distributive justice and attitude, procedural justice seems to have a greater relationship with attitude (Alexander \& Ruderman, 1987). Thus, this study is to focus on procedural justice.

Evidently, since the process of workforce restructuring encompass reduction of the workers which generates involuntary layoffs, fairness of the restructuring process becomes the most significant vocal point. This not only affects the overall image of the firm, but also the internal the laid-off workers and the remaining employees - hence the significance is severe (Wanberg et al., 1999). Particularly as the remaining employees get to observe the restructuring process first-hand, they will also get to assess and evaluate the fairness of the procedure (of the restructuring process) and the payout of the redundancy package. This process of evaluation moderates the job insecurity perception of the remaining employees and their relationship with the psychological, attitudinal and behavioral response (Brockner et al., 1987).

Daniel et al.(1998) pointed out the following factors as the significant areas of the procedural process - while in the midst of the restructuring process, whether the firm gave the workers sufficient amount of opportunity to speak; whether the public announcement was appropriate; whether the given explanation and prior information was suffice. Folger and Konovsky (1989) stresses that the more the workers feel satisfied with the given explanation and prior information on restructuring, the greater their perception of fairness in the procedure, which will positively affect their response. Furthermore, Brockner and Wiesenfeld (1996) and Davy et al. (1997) note that workers who believe restructuring was pursued based on an unfair process will be more psychologically nervous in regards to job insecurity - showing a drop in organizational commitment and work effort - than those whom believe the opposite. Therefore, it can be assumed that procedural justice within the process of restructuring will eventually moderate the relationship between job insecurity perception and withdrawal behavior. In other words, the more employees (after the restructuring has taken place) recognize and agree that the procedure was justly managed, weaker the negative effect on the task effort and withdrawal behavior influenced by the worker's job insecurity; based on the above the hypothesis is as follows:

Hypothesis 6: Procedural justice perception moderates the relationship between job insecurity perception and withdrawal behavior, such that the relationship becomes weaker when perception of procedural justice is higher. 


\section{Methodology}

\subsection{Research Model}

Based on the relationship between workforce restructuring and the individual's withdrawal behavior, the study is to prove the mediating effect of job insecurity perception and the moderating effect of career plateau and procedural justice perception.

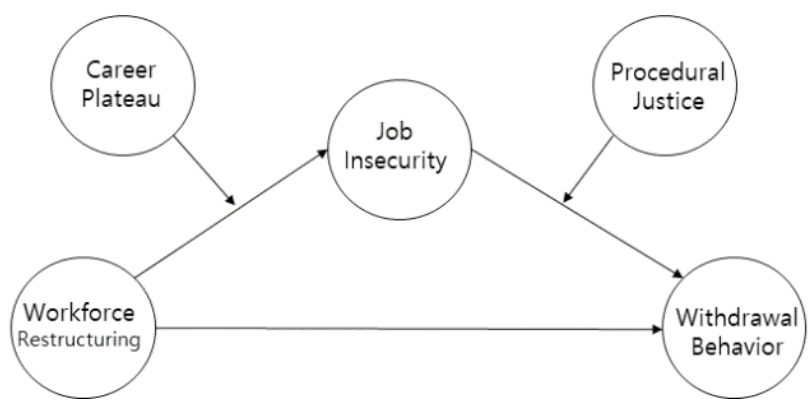

Figure 1: Research Model

\subsection{Measures}

For all questions, a 5-point Likert scale was used to measure the variable (1=most disagreeable, 5=most agreeable).

\subsubsection{Workforce Restructuring}

In workforce restructuring, as the first question, the firm is asked if they have had any layoffs of employees within the past 10 years.

\subsubsection{Job Insecurity Perception}

Five-item scale developed by Brockner, Grover, Reed, and Dewitt (1992) were used. Sample items are, "Against my will, I may have to quit the company.", "I believe the job security of our company is low."

\subsubsection{Withdrawal Behavior}

This study used the five-item scale from Colquitt, LePine and Wesson (2014) to measure psychological withdrawal behavior and the five to measure physical withdrawal behavior. Sample item for psychological withdrawal is "at work, I frequently consume my time wondering off and thinking of my private matters" For Physical withdrawal, the sample item is "Regardless of work, during the day, I end up taking long breaks and sneaking out of the office". Moreover, in order to pursue the objective of understanding the effect of restructuring on withdrawal behavior, the research will assess withdrawal behavior, based on the combined outcome of the psychological and physical withdrawal.

\subsubsection{Career Plateau}

Five-item scale for content plateau and four for structural plateau developed by Milliman (1992) and Davenport \& Russel (1994) were used to measure career plateau. The sample item for structural plateau is "I believe it will be difficult for me to get promoted in this firm"; sample for content plateau is, "I believe in my work at present, it will be difficult to get motivated again"

\subsubsection{Procedural Justice}

For the estimation, the study used six items developed by Colquitt (2001) in regards to procedural justice. Sample items for procedural justice are, "Various comments suggested by the employees are being well received"; "All matters are dealt with consistency." Value of the credibility for all the variables are showing above 7 (Ishak et al., 2018; Yang \& Moon, 2019) - Job insecurity .842, Content Plateau .868, Structural Plateau .905, Procedural Justice .890, Withdrawal Behavior .878.

\subsection{Sample}

In order to prove the hypothesis of the research, surveys were conducted on the employees of four major Korean companies in electronics, chemical and the manufacturing industry plus one domestic public company. The research was to substantiate the effect that workforce restructuring has on the attitude of the employee; sampling was done based on firms whom within the course of the recent ten years, have or have not experienced restructuring. The survey was processed via mobile and surface mail starting from 2019, June 17th 28th. Hence, responses collected from the survey were, 425 from mobile, 20 from surface mail. Amongst the 425, 3 were dishonest in its response, which became excluded from the batch, thus leaving only 422 .

\section{Analysis}

\subsection{Correlation Analysis}

According to Table 1, the correlation of the research variables trigger the expectation of that of the hypothetical. Workforce restructuring and job insecurity perception show a significant positive relationship, also job insecurity perception and withdrawal behavior show a positive as well. But, the relationship between restructuring and withdrawal behavior is not significant which may need further analysis. For example, the effect of restructuring on withdrawal 
Table 1: Results of Correlation Analysis

\begin{tabular}{|l|c|c|c|c|c|c|c|c|}
\hline & Mean & S.D & $\mathbf{1}$ & $\mathbf{2}$ & $\mathbf{3}$ & $\mathbf{4}$ & $\mathbf{5}$ & $\mathbf{6}$ \\
\hline 1. Workforce restructuring & .408 & .492 & 1 & & & & & \\
\hline 2. Job insecurity & 2.574 & .815 & $.227^{* *}$ & 1 & & & & \\
\hline 3. Job content plateau & 2.210 & .759 & .025 & $.329^{* *}$ & 1 & & & \\
\hline 4. Structural plateau & 2.838 & 1.038 & $.170^{* *}$ & $.415^{* *}$ & $.427^{* *}$ & 1 & & \\
\hline 5. Procedural justice & 3.106 & .751 & $-.169^{* *}$ & $-.370^{* *}$ & $-.422^{* *}$ & $-.324^{* *}$ & 1 & \\
\hline 6. Withdrawal behavior & 1.869 & .522 & .047 & $.146^{* *}$ & $.390^{* *}$ & $.200^{* *}$ & $-.266^{* *}$ & $-.346^{* *}$ \\
\hline
\end{tabular}

Note: ${ }^{*} p<.05,{ }^{* *} p<.01$

behavior may not have any direct impact; however, it can be assumed that job insecurity mediates the relationship.

\subsection{Regression Analysis}

\subsubsection{Relations between Restructuring, Job Insecurity and Withdrawal Behavior}

Hypothesis 1 is the direct effect restructuring has on withdrawal behavior, and based on the correlation analysis of Table1, restructuring and withdrawal behavior have no significant correlation. Hypothesis1 was not supported. On the other hand, when observing from Modell of Table2, as job insecurity perception comes out with $\mathrm{B}=0.425$, $\mathrm{t}=5.115(\mathrm{p}<0.001)$, Hypothesis 2 which believes restructuring is positively related to insecurity perception was supported. Hypothesis 3 assumes that job insecurity perception has a positive effect on withdrawal behavior. As shown on Model3 of Table2, hypothesis 3 is supported $(B=.091, \mathrm{p}<0.01)$.

In order to test the mediating effect, the results from Baron and Kenny (1986) were said to be suggested to Table 2. Based on the Model2 of Table2, the effect of restructuring on withdrawal behavior was not significant. However, the effect restructuring has had on job insecurity perception was positive (Model1, $\mathrm{B}=.425, \mathrm{p}<0.001$ ). In addition, job insecurity perception which is a mediating variable, affects withdrawal behavior, the dependent variable, in a positive manner (Model3, $\mathrm{B}=.091, \mathrm{p}<0.01$ ). Lastly, in Model 3 of Table 2 , it is evident that if job insecurity which is the mediating variable is presented, the size of the effect that restructuring has on withdrawal behavior should fall from .030 to -.010. According to Baron and Kenny (1986), the independent variable must affect the dependent variable. But according to Table 2, restructuring was not affecting withdrawal behavior. Nonetheless, Rucker, Preacher, Tormala, and Petty (2011) claim that within social psychology with hopes of proving the mediating effect based on empirical research, the precondition of which the independent variable must always affect the dependent variable, needs to be abolished. They claim that theoretical evidence is more important. This study shows that the theoretical evidence, based on previous research, enables the establishment of hypothesizes to take form. The direct effect between restructuring and withdrawal behavior may not be significant; but given that restructuring definitely affects job insecurity and job insecurity affecting withdrawal behavior, it can be understood that job insecurity fully mediates the relationship between restructuring and withdrawal behavior. Moreover via the Sobel test, having proven the significance of the mediating effect, Sobel test statistic $=2.05$ (One-tailed probability: 0.022 , Two-tailed probability: 0.044) was revealed. Hence, it can be assumed that hypothesis4 was supported.

\subsubsection{The Moderating Effect of Career Plateau}

Hypothesis 5 illustrates that career plateau could moderate the relationship between restructuring and job insecurity perception. To prevent multicollinearity, the centered average of the independent and the moderating variable were used (Choi, 2018; Lee, 2020; Wang \& Moon, 2019). The results of the analysis are shown on Table 3 and Table 4.

First of all, the result from the moderating effect of structural plateau is shown on Table 3. There has been no increase in $\mathrm{R}^{2}$. Also, the interaction factor was not significant $(B=.039, \mathrm{p}>0.05)$, thus the hypothesis 5 a was not supported.

Next, the results from the analysis on the moderating effect of content plateau is found on Table 4 . The dependent variable is job insecurity perception. When observing Model4, first of all the increase of the $\mathrm{R}^{2}$ seems significant, with also the interaction of the coefficient of regression $(\mathrm{B}=.219, \mathrm{p}<0.05)$. Thus, hypothesis $5 \mathrm{~b}$ was supported.

\subsubsection{Moderating Effect of Procedural Justice}

When observing Model 4 in Table 5, the noted outcome shows that the increase of $\mathrm{R}^{2}$ is significant, with the interaction factor also at a significance as well $(\mathrm{B}=-.126$, $\mathrm{p}<0.001)$ as well. Nevertheless, in terms of the moderating direction, it is said to be in the opposite of the hypothesis; thus, hypothesis 6 was not supported.

In order to examine in detail as to the moderating effect displayed in the opposite direction of the hypothesis, a graph 
Table 2: Regression results: Direct and Mediating Effects

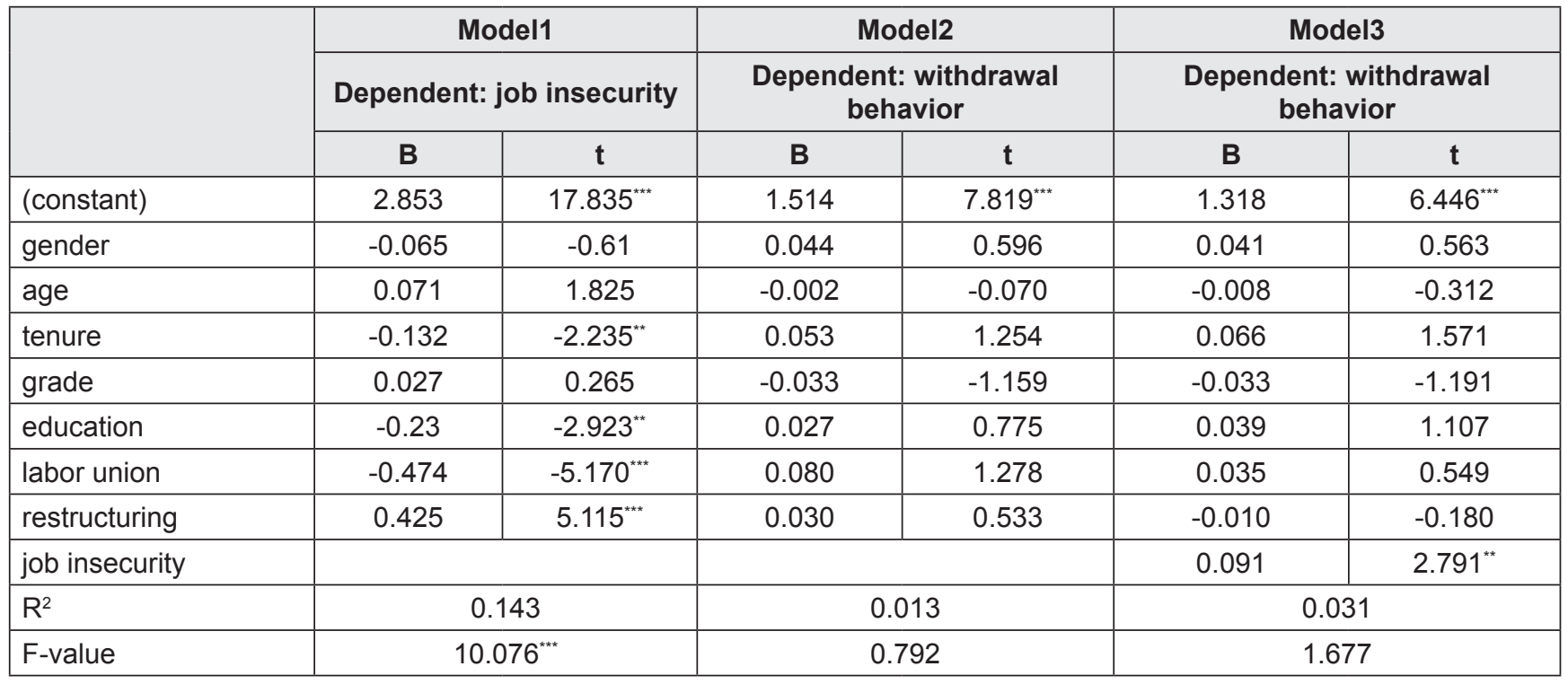

Note: ${ }^{*} p<.05,{ }^{* *} p<.01,{ }^{* * *} p<.001$

Table 3: Regression results: Moderating Effects of Structural Plateau

\begin{tabular}{|c|c|c|c|c|c|c|c|c|}
\hline & \multicolumn{2}{|c|}{ Model1 } & \multicolumn{2}{|c|}{ Model2 } & \multicolumn{2}{|c|}{ Model3 } & \multicolumn{2}{|c|}{ Model4 } \\
\hline & B & $\mathbf{t}$ & B & $\mathbf{t}$ & B & $\mathbf{t}$ & B & $\mathbf{t}$ \\
\hline constant & 2.848 & 17.294 & 2.853 & 17.835 & 2.048 & 12.643 & 2.098 & 11.519 \\
\hline gender & -.079 & -.718 & -.065 & -.610 & .166 & 1.692 & .160 & 1.623 \\
\hline age & .083 & $2.065^{\star}$ & .071 & 1.825 & -.041 & -1.132 & -.040 & -1.083 \\
\hline tenure & -.112 & $-1.841^{*}$ & -.132 & $-2.235^{\star}$ & -.148 & $-2.811^{* *}$ & -.148 & $-2.793^{* *}$ \\
\hline grade & .146 & 1.454 & .027 & .265 & .151 & 1.668 & .150 & 1.658 \\
\hline education & -.205 & $-2.531^{*}$ & -.230 & $-2.923^{* * *}$ & -.234 & $-3.334^{* * *}$ & -.234 & $-3.322^{* * *}$ \\
\hline labor union & -.432 & $-4.600^{* *}$ & -.474 & $-5.170^{\star * *}$ & -.418 & $-5.103^{\star \star \star}$ & -.416 & $-5.066^{* \star *}$ \\
\hline RES & & & .425 & $5.115^{\star \star \star}$ & .364 & $4.889^{* * *}$ & .361 & $4.842^{* \star *}$ \\
\hline SCP & & & & & .374 & $10.470^{* * *}$ & .354 & $7.231^{* * *}$ \\
\hline RESxSCP & & & & & & & .039 & .594 \\
\hline $\mathrm{R}^{2}$ & & & & & & & & \\
\hline F-value & & & & & & & & \\
\hline
\end{tabular}

Note: RES: Restructuring, SCP: Structural Career Plateau, ${ }^{*} p<.05,{ }^{* *} p<.01,{ }^{* * *} p<.001$

can be drawn up - illustrate below - based on the suggestions by Aiken and West (1991). If job insecurity perception is low, the effect of the procedural justice perception - whether it is high or low - has little impact on withdrawal behavior that the outcome bears any difference. On the contrary, if job insecurity perception is high, depending on whether it is high or low, the effect of the procedural justice perception will differ - if high, in comparison to those who have a low awareness, withdrawal behavior will be high.

\section{Results and Discussion}

\subsection{Summary of Results}

The findings from the empirical study are as follows; first, the hypothesis that restructuring effects the withdrawal behavior of the employee in a remote manner has not been supported. In other words, the attitude of the employees in regards to restructuring are not always automatically 
Table 4: Regression results: Moderating Effects of Job Contents Plateau

\begin{tabular}{|c|c|c|c|c|c|c|c|c|}
\hline & \multicolumn{2}{|c|}{ Model1 } & \multicolumn{2}{|c|}{ Model2 } & \multicolumn{2}{|c|}{ Model3 } & \multicolumn{2}{|c|}{ Model4 } \\
\hline & B & $t$ & B & $t$ & B & $\mathbf{t}$ & B & $\mathbf{t}$ \\
\hline constant & 2.848 & $17.294^{* \star *}$ & 2.853 & $17.835^{4 * *}$ & 2.079 & $11.151^{\text {t*t* }}$ & 2.265 & $11.190^{*+*}$ \\
\hline gender & -.079 & -.718 & -.065 & -.610 & -.020 & -.201 & -.029 & -.285 \\
\hline age & .083 & $2.065^{*}$ & .071 & 1.825 & .042 & 1.129 & .044 & 1.188 \\
\hline tenure & -.112 & -1.841 & -.132 & $-2.235^{\star}$ & -.117 & $-2.079^{*}$ & -.114 & $-2.052^{*}$ \\
\hline grade & .146 & 1.454 & .027 & .265 & .124 & 1.292 & .110 & 1.153 \\
\hline education & -.205 & $-2.531^{* *}$ & -.230 & $-2.923^{* *}$ & -.204 & $-2.733^{* *}$ & -.197 & $-2.651^{* *}$ \\
\hline labor union & -.432 & $-4.600^{* *}$ & -.474 & $-5.170^{* * * *}$ & -.422 & $-4.849^{*+*+}$ & -.433 & $-4.998^{*+*+*}$ \\
\hline RES & & & .425 & $5.115^{* * *}$ & 387 & $4.905^{* * *}$ & .387 & $4.939^{*+* *}$ \\
\hline JCCP & & & & & .336 & $7.109^{*+*}$ & .250 & $4.143^{*+* t}$ \\
\hline RESXJCCP & & & & & & & 219 & $2.299^{*}$ \\
\hline$R^{2}$ & & & & & & & & \\
\hline F-value & & & & & & & & \\
\hline
\end{tabular}

Note: RES: Restructuring, JCCP: Job Content Career Plateau, ${ }^{*} p<.05,{ }^{* *} p<.01,{ }^{* * *} p<.001$

Table 5: Regression results: Moderating Effects of Procedural Justice

\begin{tabular}{|c|c|c|c|c|c|c|c|c|}
\hline \multicolumn{9}{|c|}{ Dependent variable: Withdrawal behavior } \\
\hline & \multicolumn{2}{|c|}{ Model1 } & \multicolumn{2}{|c|}{ Model2 } & \multicolumn{2}{|c|}{ Model3 } & \multicolumn{2}{|c|}{ Model4 } \\
\hline & B & $t$ & B & $\mathbf{t}$ & B & $\mathbf{t}$ & B & $\mathbf{t}$ \\
\hline constant & 1.496 & $7.845^{4+*+}$ & 1.548 & $8.148^{*+*+1}$ & 1.599 & $8.594^{*+*+*}$ & 1.660 & $9.009^{*+* *}$ \\
\hline gender & .048 & .652 & .042 & .587 & .008 & .118 & .011 & .161 \\
\hline age & -.002 & -.080 & -.010 & -.401 & -.006 & -.225 & -.010 & -.398 \\
\hline tenure & .060 & 1.437 & .071 & 1.706 & .055 & 1.365 & .058 & 1.443 \\
\hline grade & -.031 & -1.124 & -.034 & -1.241 & -.023 & -.870 & -.024 & -.909 \\
\hline education & .029 & .833 & .038 & 1.089 & .017 & .499 & .018 & .522 \\
\hline labor union & .074 & 1.193 & .034 & .534 & .063 & 1.008 & .047 & .764 \\
\hline J & & & .089 & $2.836^{* *}$ & .028 & .842 & .035 & 1.050 \\
\hline PJ & & & & & -.162 & $-4.563^{* * * *}$ & -.149 & $-4.227^{\text {t*t+ }}$ \\
\hline JIxPJ & & & & & & & .126 & $3.581^{\text {tot }}$ \\
\hline $\mathrm{R}^{2}$ & & & & & & & & \\
\hline F-value & & & & & & & & \\
\hline
\end{tabular}

Note: JI: Job Insecurity, PJ: Procedural Justice, * $p<.05,{ }^{* *} p<.01,{ }^{* * *} p<.001$

negative. On the contrary, it is somewhat of the opposite, and in agreement to the empirical research done by (Mone, 1997) - believing that restructuring can give the firm the opportunity to remove insufficient management, enhance the flexibility of the organization as well as the creativity of the firm, thus upgrading the moral and productivity of the employees. Second, the empirical data shows that perception of job insecurity mediates the relationship between restructuring and withdrawal behavior. In short, withdrawal behavior will increase, as the feeling of job insecurity grows due to the impact of restructuring. Third, the results of the study revealed that content plateau had a positive moderating effect, whereas structural career plateau had not - on the relationship between restructuring and job insecurity perception. In detail, employees with a high awareness in content plateau are said to have low self-efficacy whom are 


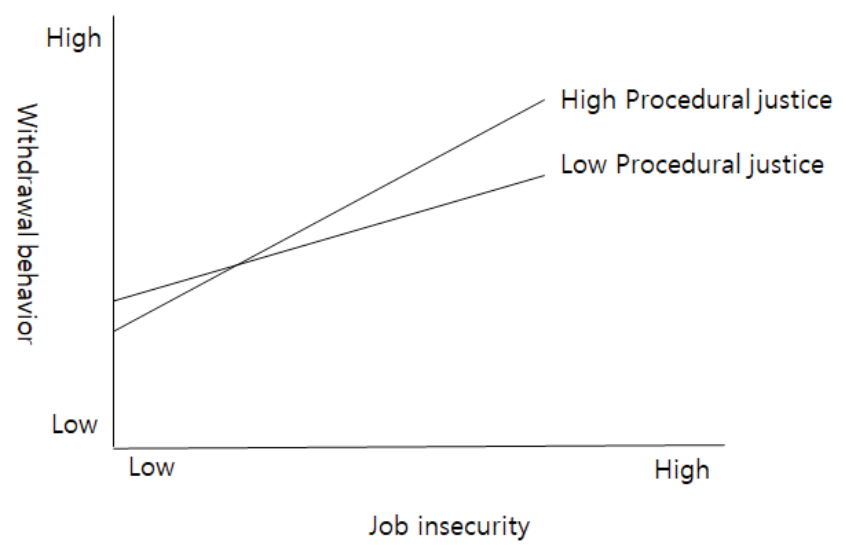

Figure 2: Interaction Effects

easily affected by the perception of job insecurity, thus the will to change oneself is very low. Fourth, as the assessment of the moderating effect of procedural justice, within the process of understanding the impact of job insecurity perception on withdrawal behavior, the suggested hypothesis was not supported - the more sensitive to the perception of job insecurity, the more negative is the individual in regards to the outcome on withdrawal behavior. If the perception of job insecurity is low, whether the perception of procedural justice is high or low, there is no meaningful effect on withdrawal behavior. But, if it is the opposite, the employee whom has a higher awareness to the perception of procedural justice, will inevitably face a stronger aftermath in its withdrawal behavior. Once again, we would like to stress that just because one has a high perception of procedural justice that automatically the individual will have a negative effect on the individual's withdrawal behavior. Herewith, depending on the scope of the individual's awareness of job insecurity perception, the procedural justice of the relations between job insecurity perception and withdrawal behavior tend to deliver differing results.

\subsection{Implications}

The theoretical implications of the research is as follows. First, it contributed in understanding the mechanism of the effect that of which workforce restructuring has rendered on the attitude and behavior of the worker. The study also examined the mediating effect of job insecurity perception in regards to the relations with restructuring and withdrawal behavior--Additionally as expressed in the above, although various empirical research has proven that workforce restructuring indeed negatively influences the attitude and behavior of the worker, there were many opposite outcomes that suggest otherwise. However, as the many of the various research mostly focus on the direct effect of restructuring, the details as to the impact on the individual, based on the process of the psychological journey is feeble (Park \& Yang, 2002). The study contributes a new addition that of which tries to explain and explore the exact process of the impact coming from restructuring in regards to withdrawal behavior; particularly via mediating job insecurity perception, stressing that the attitude and behavior of the workers are affected by restructuring. Second, the contribution of discovering a moderating variable plus enlarging the scope of the variable that can either strengthen or offset the relationship between restructuring and job insecurity perception, as well as withdrawal behavior and job insecurity perception. Henceforth for the sake of enhancing operational efficiency which can lessen the side effects from restructuring, additional research on moderating factors is in need (Mone, 1997).

Practical implications from this research are the following. First, depending on the business circumstance, if utilized with transparency and fairness, restructuring can generate opportunities for the firm, which can enable a more flexible and stronger organization. Second, a special management approach needs to be in place that can cater to the needs of the remaining employees who may suffer from job insecurity perception. Third, firms need to focus more on content plateau and find a positive direction for change. Career plateau is divided into two segments - structural and content plateau. Many are misinformed thinking that general career plateau is structural plateau. However, based on this research, we were able to discover that the moderating variable between job insecurity perception and restructuring was content plateau. Historically due to the mostly rigid vertical approach within firms, career plateau looked impossible to overcome. But with the change in society allowing a horizontal approach with more variety and the like to exist - and thus more possibilities for improvement, a need to study the content side of career plateau seems to be on the rise (Gutteridge \& Otte, 1983). For this reason, as the firm enables an enhancement of the professional capabilities, which improves motivation for the employees, as well as the structural issues of the organization, resolutions that are more efficient may be obtained.

\subsection{Limitations and Research Directions}

Despite the already expressed implications of the theoretical and of the operational, in order to improve and overcome limitations, here are some research suggestions for the future. First of all, in terms of the methodology, the paper is based on self-reporting survey; hence we cannot ignore the issue of bias on common method bias and social desirability. Therefore, there is a need to improve by enforcing a more objective approach in obtaining material either find other ways to collect the resources, or find some other venues to uphold objectivity. Second, as the results of 
the research are based on the cross-sectional study, it needs to be cautioned to interpret the results. The longitudinal analysis, which measures deliberately at a different time frame, should be helpful. Third, emotional commitment was the only result variable selected in this research; however if the three variables (emotional, continual and normative) in accordance to Meyer and Allen (1991) are considered, a more diversified outcome may be identified. Fourth, based on the empirical research, we were able to confirm that the perception of career plateau was the moderating element between the relationship of restructuring and job insecurity perception. Such a result implies that the process of restructuring, by utilizing job insecurity perception as the mediator, in order to influence the dependent variable, can be moderated by the outcomes of career plateau. In short, it is possible to mediate the moderated job insecurity. Since the current study was in substantiating only the moderating effect of career plateau, with ongoing efforts of a more detailed development of theory along with reviews from empirical research, in the future it would be meaningful if a hypothesis of the moderated mediating effect could be established. Lastly, an analysis in regards to the changing of generations with a specified focus of each societal group, as is the likes of the millennials is strongly recommended - the differentiated stance of the millennials are extremely unique that the attitude and behavior when facing ordeals such as restructuring can be the much anticipated turning point for the future.

\section{References}

Aiken, L. S. \& West, S. G. (1991). Multiple Regression: Testing and Interpreting Interactions. Sage.

Alexander, S., \& Ruderman, M. (1987). The role of procedural and distributive justice in organizational behavior. Social Justice Research, 1(2), 177-198.

Arnold, H. J., \& Feldman, D. C. (1982). A multivariate analysis of the determinants of job turnover. Journal of Applied Psychology, 67(3), 350-360.

Ashford, S. J., Lee, C., \& Bobko, P. (1989). Content, cause and consequences of job insecurity: A theory-based measure and substantive test. Academy of Management Journal, 32(4), 803-829.

Bardwick, J. M. (1986). The plateauing trap: How to avoid it in your career, AMACOM: New York.

Baron, R. M., \& Kenny, D. A. (1986). The moderator-mediator variable distinction in social psychological research: Conceptual, strategic, and statistical considerations. Journal of Personality \& Social Psychology, 51(6), 1173-1182.

Blau, P. M. (1964). Exchange and power in social life. New York: Wiley.

Brockner, J. (1988). The effect of work layoff on survivors: Research, theory, and practice. Research in Organizational Behavior, 10, 213-256.
Brockner, J., Grover, S. L., Reed, T., DeWitt, R., \& O'Malley, M. (1987). Survivors' reactions to layoffs: We get by with a little help for our friends. Administrative Science Quarterly, 32(4), 526-541.

Brockner, J., Grover, S. L., Reed, T. F., \& DeWitt, R. L. (1992). Layoffs, job insecurity, and survivors' work effort: Evidence of an invested U relationship, Academy of Management Journal, 35(2): 413-425.

Brockner, J., Tyler, T. R., \& Cooper-Schneider, R. (1992). The influence of prior commitment to an institution on reactions to perceived unfairness: The higher they are, the harder they fall. Administrative Science Quarterly, 37(2), 241-261.

Brockner,J.,\&Wiesenfeld,B.M.(1996).Anintegrativeframeworkfor explaining reactions to decisions: Interactive effects of outcomes and procedures. Psychological Bulletin, 120(2): 189-208.

Cameron, K. S. (1994). Strategies for successful organizational downsizing. Human Resource Management, 33(2), 189-211.

Cascio, W. F. (1993). Downsizing, what do we know? What have we learned? Academy of Management Executive, 7(1), 95-104.

Choi, Y. (2018). The influence of bullying on burnout through workaholism and perceived organizational support. Journal of Business Economics and Environmental Studies, 8(3), 13-21.

Choi, M., \& Gurung, A. (2019). Human resource management in Nepal: A Delphi study. Journal of Business Economics and Environmental Studies, 9(1), 5-12.

Colquitt, J. A. (2001). On the dimensionality of organizational justice: A construct validation of a measure. Journal of Applied Psychology, 86(3), 386-400.

Colquitt. J., LePine. J., \& Wesson. M. (2014). Organizational Behavior Improving Performance and Commitment in the Workplace (4th ed). New York McGrow-Hill.

Daniel, P. S., Ellard, J. H., \& Kelln, B. R. C. (1998). Third party perceptions of a layoff: Procedural, derogation and retributive aspects of justice. Journal of Applied Psychology, 83(1), 119-127.

Davenport, L., \& Russell, J. E. A. (1994). Examining the relationship between career plateauing and job attitudes, In annual meeting of the Academy of Management, Dallas, Texas.

Davy, J. A., Kinicki, A. J., \& Scheck, C. L. (1997). A test of job security's direct and mediated effects on withdrawal cognitions. Journal of Organizational Behavior, 18(4), 323-349.

Dekker, S. W. \& Schaufeli, W. B. (1995). The effects of job insecurity on psychological health and withdrawal: a longitudinal study. Australian Psychologist, 30(1), 57-63.

Ferrie, J. E., Shipley, M. J., Marmot, M. G., Stansfeld, S., \& Smith, G. D. (1998). The health effects of major organisational change and job insecurity. Social Science \& Medicine, 46(2), 243-254.

Folger, R. G., \& Cropanzano, R. (1998). Organizational Justice and Human Resource Management, Thousand Oaks, CA: sage.

Folger, R., \& Konovsky, M. A. (1989). Effects of procedural and distributive justice on reactions to pay raise decisions. Academy of Management Journal, 32(1), 115-130. 
Forbes, D. (1985). The no-layoff payoff. Dun's Business Month, 126(1), 64-66.

Greenhalgh, L., \& Rosenblatt. Z. (1984). Job insecurity: Toward conceptual clarity. Academy of Management Review, 9(3), 438-448.

Gutteridge, T. G. \& Otte, I. L. (1983). Organizational Career Development: State of the Practice, Washington D.C.: ASTD Press.

Heaney, C. A., Israel, B. A., \& House, J. S. (1994). Chronic job insecurity among automobile workers: Effects on job satisfaction and health. Social Science \& Medicine, 38(10), 1431-1437.

Ishak, Y., Ismail, A., Abdullah, A. A., Samsudin, A., \& Mohamed, K. R. (2018). Mediation of distributive justice on dyadic relationship between leaders and followers with personal outcomes. Journal of Business Economics and Environmental Studies, 8(4), 29-35.

Ivancevich, J. M., \& Matteson, M. T. (1980). Optimizing human resources: A case for preventive health and stress management. Organizational Dynamics, 9(2), 5-25.

Jung, M. H. (2017). The effect of psychological well-being on life satisfaction for employees. International Journal of Industrial Distribution \& Business, 8(5), 35-42.

Jung, H. S., \& Moon, J.S. (2015). Case study on decision-making process for M\&A in small and medium companies. Journal of Distribution Science, 13(10), 65-72.

Kets de Vries, F. R., \& Balazs, K. (1997). The downside of downsizing. Human Relations, 50(1), 11-50.

Lee, J. P. (2020). A study on the moderating effect that value congruence influences organizational performance. International Journal of Industrial Distribution \& Business, 11(3), 51-62.

Lee, M. H. (2018). Effects of organizational and interpersonal relations on job satisfaction of social workers. International Journal of Industrial Distribution \& Business, 9(6), 25-35.

Lentz, E. \& Allen, T. D. (2009). The role of mentoring others in the career plateauing phenomenon. Group \& Organizational Management, 34(3), 358-384.

Mckinley, W., Sanchez, C. M., \& Schick, A. G. (1995). Organizational downsizing: Constraining, cloning, learning. Academy of Management Executive, 9(3), 32-42.

Meckler, M., Drake, B. H., \& Levinson, H. (2003). Putting psychology back into psychological contracts. Journal of Management Inquiry, 12(3), 217-228.

Meuse, K. P., Vanderheiden, P. A., \& Bergmann, T. J. (1994). Announced layoffs: Their effect on corporate financial performance. Human Resource Management, 33(4), 509-530.

Meyer, J. P., \& Allen, N. J. (1991). A three-component conceptualization of Organizational commitment. Human Resource Management Review, 1(1): 61-89.

Milliman, J. F. (1992). Causes, consequences, and moderating factors of career plateauing. Unpublished doctoral dissertation, University of Southern California.

Mone, M. A. (1997). How we get along after the downsizing: Post-downsizing trust as a double-edged sword. Public Administration Quarterly, 21(3), 309-336.
Morrison, E. W., \& Robinson, S. L. (1997). When employees feel betrayed: A model of how psychological contract violation develops. Academy of Management Review, 22(1), 226-256.

Mowday, R. T., Porter, L. W., \& Steers, R. (1982). Organizational Linkage: The Psychology of Commitment, Absenteeism and Turnover. New York, NY.

Park, J., \& Yang, H. (2002). Antecedents and outcomes of job insecurity: A study on employees who survive from business restructuring. Korean Journal of Management, 26(2), 25-60.

Robinson, S, L, \& Rousseau, D. M. (1994). Violating the psychological contract: Not the exception but the norm. Journal of Organizational Behavior, 15(3), 245-259.

Rosenblatt, Z., \& Ruvio, A. (1996). A test of a multidimensional model of job insecurity: The case of Israeli teachers. Journal of Organizational Behavior, 17(S1), 587-605.

Roskies, E., \& Louis-Guerin, C. (1990). Job insecurity in managers: Antecedents and consequences. Journal of Organizational Behavior, 11(5), 345-359.

Rousseau, D, M. (1995). Psychological Contracts in Organizations, Thousand Oaks: Sage.

Rucker, D. D., Preacher, K. J., Tormala, Z. L., \& Petty, R. E. (2011). Mediation analysis in social psychology: Current practices and new recommendations. Social and Personality Psychology Compass, 5(6), 359-371.

Schweiger, D. L., \& Invancevich, J. M. (1985). Human resources: The forgotten factor in mergers and acquisition. Personnel Administrator, 30(11), 47-61.

Shore, L. M., \& Tetrick, L. (1994). The psychological contract as an explanatory framework in the employment relationship. In Cooper, C. \& Rousseau, D. (Eds.) Trends in Organizational Behavior, 9, Wiley New York, 91-109.

Singh, R. (1998). Redefining psychological contracts with the U.S. work force: A critical task for strategic human resource management planners in the 1990s. Human Resource Management, 37(1), 61-69.

Turnley, W. H., \& Feldman, D. C. (1998). Psychological contract violations during corporate restructuring. Human Resource Management, 37(1), 71-83.

Wanberg, C. R., Gavin, M. B., \& Bunce, L. W. (1999). Perceived fairness of layoffs among individuals who have been laid off: A longitudinal study. Personnel Psychology, 52(1), 59-84.

Wang, H., \& Moon, J. (2019). The Relationship between Work Values and Entrepreneurial Attitudes: Implications for the Distribution Industry, Journal of Distribution Science, 17(3), 57-67.

West, M., Nicholson, N., \& Fees, A. (1990). The outcomes of downward managerial mobility. Journal of Organizational Behavior, 11(2), 119-134.

Yang, X., \& Moon, J. (2019). The Effects of LMX and Feeling Trusted on Job Performance and Workplace Ostracism Among Salespeople, Journal of Distribution Science, 17(4), 41-50. 